\title{
Aflatoxins: biosynthesis, prevention and eradication
}

\author{
Juliana Šimončicová, Barbora Kaliňáková, Svetlana Kryštofová \\ Institute of Biochemistry and Microbiology, Faculty of Chemical and Food Technology, \\ Slovak University of Technology in Bratislava \\ juliana.simoncicova@stuba.sk
}

\begin{abstract}
Filamentous fungi belonging to Aspergilli genera produce many compounds through various biosynthetic pathways. These compounds include a spectrum of products with beneficial medical properties (lovastatin) as well as those that are toxic and/or carcinogenic which are called mycotoxins. Aspergillus flavus, one of the most abundant soil-borne fungi, is a saprobe that is able growing on many organic nutrient sources, such as peanuts, corn and cotton seed. In many countries, food contamination by A. flavus is a huge problem, mainly due to the production of the most toxic and carcinogenic compounds known as aflatoxins. In this paper, we briefly cover current progress in aflatoxin biosynthesis and regulation, pre- and postharvest preventive measures, and decontamination procedures.
\end{abstract}

Keywords: aflatoxins, Aspergillus flavus, mycotoxin

\section{Introduction}

Aflatoxins (AF) are mycotoxins that belong to a group of highly oxygenated polyketides mainly produced by Aspergillus flavus and Aspergillus parasiticus, even though some studies recently demonstrated the importance of species such as Aspergillus nomius, Aspergillus minisclerotigenes and Aspergillus arachidicola as AF producers (Gallo et al., 2016). It is estimated that at least a quarter of the world's food crops is contaminated by mycotoxins; leading to a large economical loss worldwide (Kumar et al., 2008; Njobeh et al., 2009). A. flavus is one of the most notorious and economically devastating producers of AF. In the United States alone, A. flavus causes more than a billion-dollar loss per year due to crop contamination (Cary et al., 2015).

AF belong to the most toxic and carcinogenic toxins, creating a global food safety issue (Payne and Brown, 1998; Bennett et al., 2003). More than 20 kinds of $\mathrm{AF}$ have been identified among which four major $\mathrm{AF}$, aflatoxin $\mathrm{B}_{1}\left(\mathrm{AFB}_{1}\right)$, aflatoxin $\mathrm{B}_{2}\left(\mathrm{AFB}_{2}\right)$, aflatoxin $\mathrm{G}_{1}\left(\mathrm{AFG}_{1}\right)$ and aflatoxin $\mathrm{G}_{2}\left(\mathrm{AFG}_{2}\right)$ have been extensively studied. While A. flavus generally produces only the type $\mathrm{B} A \mathrm{AF}$, other species, such as $A$. parasiticus and $A$. nomius can produce both $\mathrm{B}$ and G AF (Kumeda et al., 2003; Varga et al., 2003). $\mathrm{AFB}_{1}$, which is produced by A. flavus, is the most mutagenic and carcinogenic natural compound known (Georgianna and Payne, 2009; Cary et al., 2015). $\mathrm{AFB}_{1}$ is converted in vivo by cytochrome P-450 monooxygenases into reactive $\mathrm{AFB}_{1}-8,9$ epoxide, which binds to cellular macromolecules and causes injury to the periportal regions of the liver leading to liver cancer development (Ueng et al., 1995). Ingestion of food products contaminated with AF has been associated with hepatotoxicity, teratogenicity, immunosuppression, and liver cancer (Cary et al., 2015; Gilbert et al., 2016).

\section{Aflatoxin biosynthesis and regulation}

The mechanism of AF biosynthesis has been extensively studied, and recent investigations have shown that about 30 clustered genes and more than 23 steps of enzymatic reactions are involved in the AF biosynthetic pathway (Georgianna and Payne, 2009; Yu, 2012; Yang et al., 2015). AF biosynthesis is extremely sophisticated (Klich, 2007; Yang et al., 2015). Generally, the AF biosynthesis genes of the most known AF producers, A. flavus and A. parasiticus, are highly homologous and the order of 25 genes within the AF gene clusters in the two organisms has been shown to be identical (Jiujiang et al., 1995). The genes encoding the pathway for AF biosynthesis are encoded by the $75 \mathrm{~kb}$ gene cluster in A. flavus. To date, 29 AF biosynthetic genes have been identified within the gene cluster (Yu et al., 2004; Cleveland et al. 2009) and their functions elucidated. The entire AF biosynthetic pathway consists of at least 21 enzymatic reactions (Trail et al., 1995). The excerpt of AF biosynthetic pathway and the most prominent genes are summarized in the Figure 1 and Table 1.

The AF pathway genes which are clustered in one locus in genomes of A. flavus and A. parasiticus are expressed simultaneously (Brown et al., 2009). The expression of the AF structural genes is a complex process regulated by the positive-acting regulatory gene, aflR, which is localized in the middle of the $\mathrm{AF}$ gene cluster. The aflS gene, adjacent to aflR, was found to be interacting with aflR and participating in 


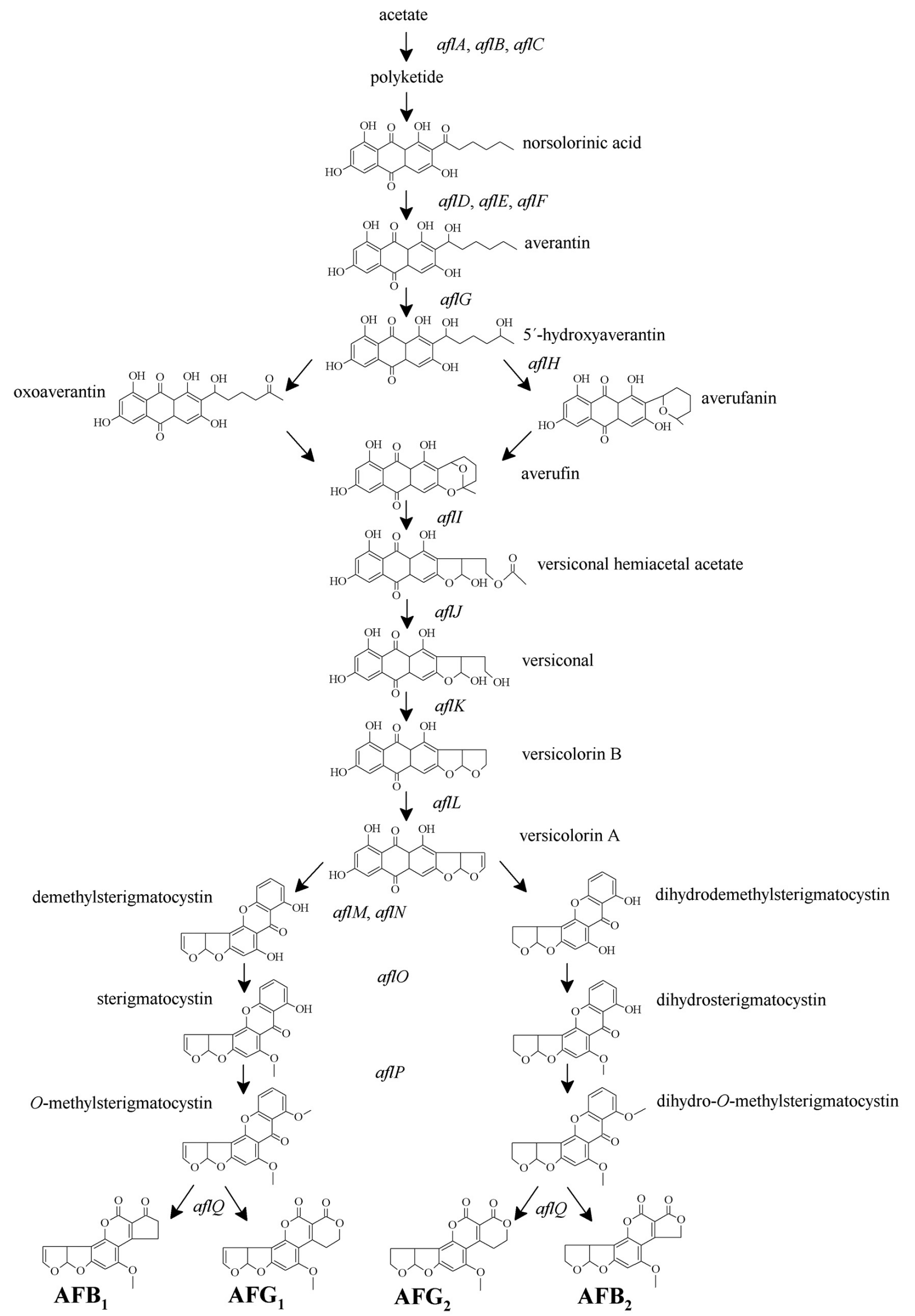

Fig. 1. AF biosynthetic pathway and genes encoding the enzymes catalyzing consecutive steps in the AF biosynthesis (Yu et al. 2004, modified). 
the regulation of transcription (Meyers et al., 1998). Other genes, non-coded by the aflatoxin gene cluster, have been shown to be involved in regulation of the aflatoxin gene expression (Table 2). Global regulators LaeA and VeA positively regulate aflatoxin production (Yang et al., 2016). Deletion of veA in A. flavus and A. parasiticus strains caused disruption in aflatoxin production. Hundreds of genes in $A$. flavus are regulated by VeA and are also influenced by the presence or absence of light, including developmental genes and secondary metabolite gene clusters (Maplestone et al., 1992; Hicks et al., 1997; Calvo et al., 2002; Bayram et al., 2008; Bayram and Braus, 2012; Bayram et al., 2012; Cary et al., 2015). The putative methyltransferase LaeA and the velvet protein VeA have been shown to interact with each other to form a protein complex designated velvet (Bayram et al., 2008; Calvo and Cary, 2015). Global regulator $\mathrm{VeA}$ interacts with other velvet domaincontaining proteins to regulate the expression of several crucial genes required for the synthesis of mycotoxins, including AF, cyclopiazonic acid, and aflatrem (Duran et al., 2009).

The $d m t A$ mutants deficient in DNA methyltransferase exhibited decreased asexual reproduction and aflatoxin biosynthesis in comparison with the wild-type strain A. flavus, suggesting that the $d m t A$ knockout affected the transcriptional level of genes in the aflatoxin cluster. Moreover, $d m t A$ deletion induced such changes in seed infection, which resulted in more conidia (asexual reproduction cells) formation in crop seeds in comparison to the wildtype strain (Yang et al., 2016). The asexual development and AF production were regulated also by the transcription factor NsdC. The recent studies on the transcriptional regulator $n s d C$ have elevated its role to a globally-acting transcription factor that is a key coordinator of both conidia formation and aflatoxin metabolism in A. flavus (Gilbert et al., 2016).

\section{Environmental factors affecting aflatoxin biosynthesis}

The production of AF has been shown to be regulated by several means. However, the biological role of AF and various other secondary metabolites in A. flavus physiology and/or interactions with other organisms including plant host-pathogen interactions is still not clear. Although, it could be hard to pinpoint the environmental conditions leading to the $\mathrm{AFB}_{1}$ synthesis in A. flavus, there is evidence that oxidative stress is one of the main players (Reverberi et al., 2008). The regulation of the AF biosynthesis in various Aspergillus spp. has been extensively studied, and has been shown to be connected to reactive oxygen species (ROS) formation and oxidative stress responses (Zaccaria et al., 2015). The AF biosynthesis is not only regulated by intracellular ROS of different origins (Reverberi et al., 2006; Grintzalis et al., 2014), but the AF biosynthetic pathway itself may serve as a source of ROS due to involvement of P450 enzymes (Roze et al.,

Tab. 1. AF biosynthesis genes and intermediates (Yu et al., 2004, modified).

\begin{tabular}{lll}
\hline Gene & Enzyme & Product of reaction \\
\hline aflA & Fatty acid synthase $\alpha$ & Polyketide backbone from acetate \\
aflB & Fatty acid synthase $\beta$ & Polyketide backbone from acetate \\
aflC & Polyketide synthase & Polyketide \\
aflD & Reductase & Averantin \\
aflE & Norsolorinic acid reductase & Averantin \\
aflF & Dehydrogenase & Averantin \\
afl & P450 monooxygenase & 5 -Hydroxyaverantin \\
aflH & Alcohol dehydrogenase & Averufin \\
aflI & Oxidase & Versiconal hemiacetal acetate \\
aflJ & Esterase & Versiconal \\
aflK & Versicolorin B synthase & Versicolorin B \\
aflL & Desaturase & Versicolorin A \\
aflM & Dehydrogenase & Demethylsterigmatocystin \\
afl $N$ & Monooxygenase & Demethylsterigmatocystin \\
aflO & O-methyltransferase B & Sterigmatocystin, Dihydrosterigmatocystin \\
aflP & O-methyltransferase A & O-methylsterigmatocystin, \\
aflQ & Oxidoreductase & Dihydro- $O$-methylsterigmatocystin \\
\hline & & AFB, AFB $_{2}$, AFG $_{1}$, AFG $_{2}$ \\
\hline
\end{tabular}


2015). Disruption in the AF biosynthetic pathway at an early, middle, or late steps, affected quantities of detected ROS (Roze et al., 2015).

AF production apparently could direct the ROS excess accumulated during cell ageing, or as a response to external insults, into extending the fun-

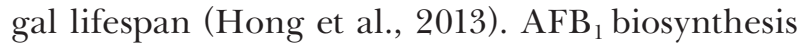
is controlled by a wider array of oxidative stress factors, such as lipid hydroperoxide, superoxide, and hydroxyl and thiol radicals (Grintzalis et al., 2014). Grintzalis et al. 2014 observed that (i) oxidative stress regulates fungal sexual development, as implied by its inhibition by ROS and thiol redox state, and that (ii) the $\mathrm{AFB}_{1}$ biosynthesis and sexual development are coregulated by the oxidative stress. Numerous studies have shown that the AF production can be exacerbated by ROS and their reactive products including oxylipins and peroxidized lipids (Fabbri et al., 1983; Gao and Kolomiets, 2009). Additional studies have also demonstrated that toxigenic fungal isolates exhibit elevated oxygen consumption, greater mycelial ROS accumulation, and a higher peroxisome number than atoxigenic isolates, indicating a reasonable link between ROS and AF production (Jayashree and Subramanyam, 2000; Reverberi et al., 2008; Roze et al., 2011; Reverberi et al., 2012; Roze et al., 2015). In addition, the elite atoxigenic biological control isolates of $A$. flavus have been able to tolerate higher levels of peroxide-induced oxidative stress than other tested atoxigenic isolates.

ROS and their reactive products including peroxidized lipids (oxylipins) have been shown to induce and to be required for AF production (Jayashree and Subramanyam, 2000). In some filamentous fungi, the pathways related to the oxidative stress and oxylipins production are involved in the process of hostfungus interactions. Moreover, the recent studies have also shown that the production of oxylipins in filamentous fungi and yeasts is also related to the development of an organism itself and to molecular mechanisms of communication between a host and a

Tab. 2. Regulators of aflatoxin gene expression.

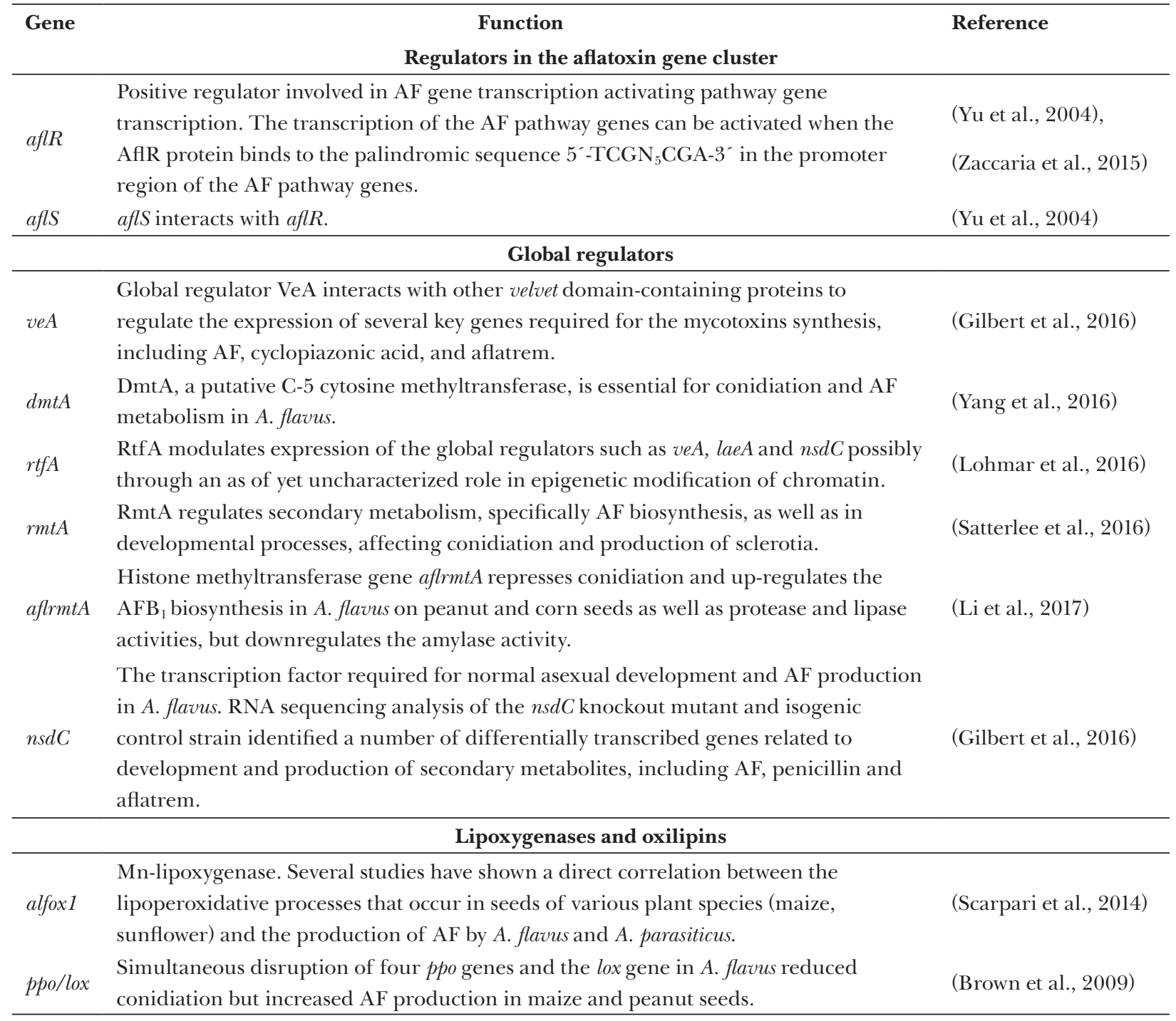


fungus at the cellular level. Lipoxygenases belong to the main oxylipin-producing enzymes in organisms. Lipoperoxidation seems to play an important role in the induction of mycotoxins, including AF (Scarpari et al., 2014). Several studies have shown a direct correlation between the lipoperoxidative processes that occur in the seeds of various plant species (maize, sunflower) and the production of AF by A. flavus and A. parasiticus (Fabbri et al., 1983; Burow and Nesbitt, 1997; Duran et al., 2009).

\section{Prevention and decontamination}

Maize and nuts are often invaded by Aspergillus fungal species before and after harvest and during storage. Aspergillus species can be commonly found in the soil, which acts as a source for infecting developing maize kernels during the growing season (Horn, 2007). Minimizing fungal infection is essential to manage mycotoxin contamination of food and feed (Table 3), but many control methods are not without their own safety concerns for the animals and consumers (Temba et al., 2016).

\section{Fungicides}

Fungi are usually controlled by antifungal agents during preharvest stage; however, these agents often possess adverse effects on the human health and the environment (Vicente, 2004). Repeated usage can also cause some fungi to develop resistance against broad spectrum of fungicides such as benzimidazoles, prochloraz, and imazalil. Using chemical fungicides is even more harmful when applied during the postharvest period, as there is only a short interval between application of treatment and consumption.

\section{Essential oils, polyphenols and alkaloids}

Essential oils (EOs) are aromatic substances which are obtained from various plant parts by steam distillation. Many of EOs exhibit antifungal, antibacterial, and antiviral activity (Astani et al., 2010; Khaledi et al., 2015). Several studies investigated the antifungal activity of various EOs against $A$. flavus (Pekmezovic et al., 2015; Dehghanpour-Farashah and Taheri, 2016; Kedia et al., 2016; Shen et al., 2016; Al-Shahrani et al., 2017).

Piperine, a major component of black and long peppers, has been previously demonstrated as an $\mathrm{AFB}_{1}$ biosynthesis inhibitor. The aflatoxin production and fungal growth were inhibited by piperine in a dose-dependent manner. Expression analysis of the AF gene cluster demonstrated that almost all genes were down regulated (Caceres et al., 2017). Exposure to piperine also resulted in decreased transcript levels of the global regulator veA together with an overexpression of genes coding several basic leucine zipper (bZIP) transcription factors such as atf $A$, atfB and $a p-1$ and genes belonging to superoxide dismutase and catalase families (Caceres et al., 2017).

In total, 366 and 87 genes of A. flavus were significantly up- and down- regulated, respectively, when the fungus underwent exposure to resveratrol, a polyphenol isolated from red wine (Wang et al., 2015). Resveratrol significantly increased the activity of antioxidative enzymes that subsequently destroyed radicals, leading to decrease of the AF production. The expression of A. flavus genes that are required for developmental and secondary metabolic processes was also affected which resulted in the AF production decline and aberration in fungal growth and reproduction (Wang et al., 2015).

\section{Biological control}

To date, the only cost-effective, environmentally friendly technology to reduce AF accumulation of crops is the application of atoxigenic isolates of A. flavus (lacking the AF production) as biocontrol agents to displace aflatoxigenic fungi producing AF

Tab. 3. Prevention and decontamination strategies to reduce AF.

\begin{tabular}{ll}
\hline Stage & Intervention \\
\hline & $\bullet$ good agricultural practices \\
& $\bullet$ chemical control (fungicides) \\
& - biocontrol (atoxigenic fungi) \\
& $\bullet$ selection of resistant cultivars \\
& - antioxidant application \\
& $\bullet$ storage condition and packaging improvement \\
& $\bullet$ cleaning \\
& $\bullet$ crop segregation and separation \\
& $\bullet$ chemical control (fungicides, essential oils, polyphenols, ammoniation, etc.) \\
& $\bullet$ UV light irradiation \\
Postharvest & microwave irradiation \\
& low temperature plasma treatment
\end{tabular}


(Dorner, 2009). Crops are typically infected by multiple A. flavus strains (Atehnkeng et al., 2016) and atoxigenic isolates applied on growing crops may compete with toxigenic strains during co-infection, and also interfere with the AF accumulation in plants. For certain atoxigenic isolates, competitive exclusion is sufficient to explain the AF reduction during co-infection (Hruska et al., 2014) in a process that is aided by initial host interaction (Mehl and Cotty, 2011). However, some atoxigenic isolates are capable of even more significant reduction of $\mathrm{AF}$ during co-infection. This occurs through unknown mechanisms and typically provides an additional 10-20\% reduction in AF (Mehl and Cotty, 2010).

\section{Enhancement of plant resistance}

Number of studies has focused on the host plant and has revealed many genes and molecules that control the intricate process of AF biosynthesis in A. flavus (Amaike and Keller, 2011; Astoreca et al., 2014; Torres et al., 2014; Bhatnagar-Mathur et al., 2015; Wang et al., 2015). Enhancement of maize resistance to A. flavus infection is a desirable feature to reduce AF contamination at the preharvest stage of maize production. The maize resistance to $A$. flavus is a quantitative trait involving co-expression of many genes (Kelley et al., 2012). Identification of controlling genes and the gene network interaction is essential to the development of DNA markers and the transfer of maize resistance into commercial maize lines (Asters et al., 2015).

The application of atoxigenic A. flavus strains in maize fields has been shown to be an effective strategy for controlling contamination of $\mathrm{AF}$ as well. The study monitored the expression levels of 18 defence genes against toxigenic and atoxigenic A. flavus strains in developing maize kernels over a time course of $96 \mathrm{~h}$ after inoculation. A stronger upregulation of genes encoding pathogenesisrelated proteins, oxidative stress-related proteins, transcriptional factors and lipoxygenases were observed in response to the atoxigenic strain. These results suggested that overexpression of maizedefence-associated genes observed in response to the atoxigenic strain could contribute to an AF reduction. The identification of genes significantly affecting the plant resistance to A. flavus or AF accumulation would accelerate the development of resistant cultivars (Lanubile et al., 2017).

\section{Storage conditions}

There are multiple factors involved in the growth and development of $A$. flavus and in the biosynthesis of these secondary metabolites, such as humidity, temperature, presence of oxygen and carbon dioxide, substrate composition, loss of integrity of the grains or crops caused by insects or mechanical/ thermal damage, fungal concentration and the interaction between fungal species that cohabitate in the same ecological niche. Water activity (aw) and temperature are limiting factors for fungal growth and AF production during storage. The effects of temperature and aw on AF production by A. flavus grown on various agricultural crops and food has been widely studied (Molina and Giannuzzi, 2002; Arrus et al., 2005; Ribeiro et al., 2006; Giorni et al., 2008). For the growth of A. flavus in shelled peanuts for example, 0.98 was optimal aw, and $37^{\circ} \mathrm{C}$ was the optimum temperature. The maximum amount of $\mathrm{AFB}_{1}$ however in peanuts was obtained at $28^{\circ} \mathrm{C}$ and aw 0.96 (Liu et al., 2017). The real-time analysis showed that 16 of 25 genes had highest expression levels at $28{ }^{\circ} \mathrm{C}$ under aw 0.92 , while only 9 genes had highest expression levels at $37^{\circ} \mathrm{C}$ under aw 0.92. Compared with $37^{\circ} \mathrm{C}$, all aflatoxin biosynthetic pathway genes were downregulated at $42{ }^{\circ} \mathrm{C}$. The results of this study also suggested that $\mathrm{AFB}_{1}$ production in peanut kernels could occur over a wider range of aw and temperature. From a food safety point of view, the data obtained in the studies investigating the effect of storage conditions on the AF production can be used to optimize certain food technological processes and develop prevention strategies to control AF in grains and other products.

\section{UV light irradiation}

The AF have been found to be very sensitive to the treatment with the UV light and the UV light was found to be the most effective method used in reduction of AF level in wheat and to protect grains from deterioration during storage (Ghanghro et al., 2016). Several studies demonstrated that the AF production could be affected by the light without damaging nutritional qualities of food (Samarajeewa et al., 1990). Bennett et al. (1981) found that no AF production was observed under light at temperature 35 and $40{ }^{\circ} \mathrm{C}$, whereas fungal growth was good at those temperatures.

Wheat at all stages of growth in field condition as well as during storage is subjected to deterioration due to the fungal colonization which not only contaminates wheat but is also hazardous to humans and animals when consumed as food or feed. Therefore, the efforts have been made to reduce the AF contamination load from wheat. The UV radiation in time dependent dose $(0,5,10,20,40,80$ and $160 \mathrm{~min})$ was used to decontaminate $\mathrm{AF}$ in open grains and the grains packed in sacks. The results demonstrated $80-90 \%$ and $65-73 \%$ respectively, decrease in the AF levels in both wheat samples exposed to the UV light (Ghanghro et al., 2016). 


\section{Microwave irradiation}

In attempt to decontaminate stored food, other physical methods, including microwave irradiation (MWI), have been applied. Lee et al. (2017) investigated the effects of the MWI $(2.450 \mathrm{MHz}, 700 \mathrm{~W}$, for $10-50 \mathrm{~s}$ ) on inactivation of A. flavus and A. para siticus $(7-8 \log )$ on brown rice and barley and the quality of these samples. The colony counts of both strains were significantly reduced in dose dependent manner. It has been shown that $20 \mathrm{~s}$ treatment by the MWI at $2.450 \mathrm{MHz}, 700 \mathrm{~W}$ could be effective for $>90 \%$ reduction of fungi without causing decline in the colour, moisture content, and sensory qualities of these cereals. However, values for the colour, appearance and texture were significantly reduced when treated with 40-50 s MWI.

\section{Low temperature plasma treatment}

A novel alternative for inactivation of microorganisms on grains and crops recently represents the plasma treatment, where a variety of energetic species (charged and excited species, reactive neutrals and UV photons) is formed. Each of these species alone can deactivate or disintegrate microorganisms, but they are more effective in synergetic application (Fridman et al., 2008). Over the last decade, interests and intensity of research on potential applications of the plasma have increased significantly in the field of food engineering and food processing. Development of new plasma sources, specifically those that allow generation of nonthermal plasma near ambient temperatures, have been considered as suitable for heat sensitive food surfaces.

Dasan et al. (2016) decontaminated A. flavus on the surface of hazelnuts using the atmospheric pressure fluidized bed plasma (APFBP). Significant reductions in A. flavus and in A. parasiticus were achieved after 5 min treatments at $100 \mathrm{~V}-25 \mathrm{kHz}(655 \mathrm{~W})$ by using dry air as the plasma forming gas. The decontamination effect of APFBP on A. flavus and A. parasiticus spores inoculated on hazelnuts increased with the applied reference voltage and the frequency. No changes or only slight reductions were observed in A. flavus and A. parasiticus load during the storage of plasma treated hazelnuts, whereas fungi continued to grow under storage conditions on the control samples (Dasan et al., 2016).

Zahoranová et al. (2016) investigated effect of cold atmospheric pressure plasma (CAPP) treatment on the germination, production of biomass, vigour of seedlings, uptake of water of wheat seeds (Triticum aestivum L. cv. Eva). The growth inhibition effect of CAPP on the surface microflora of wheat seeds increased with the increase of the treatment time. The sample exposure to $180 \mathrm{~s}$ CAPP treatment signifi- cantly reduced growth of toxinogenic $A$. flavus. The lethal effect on conidia was observed after the $240 \mathrm{~s}$ CAPP seeds treatment (Zahoranová et al., 2016).

Influence of cold plasma on the $A$. parasiticus and $A$. flavus growth and AF production have been investigated as an alternative to chemical interventions and thermal treatments (Devi et al., 2017). Artificially inoculated fungal species onto the groundnuts were treated with the air plasma at $40 \mathrm{~W}$ and $60 \mathrm{~W}$ power levels at various time periods. After the plasma treatment, inactivation of $A$. parasiticus and A. flavus was examined and the concentration of AF produced was analysed using HPLC. $97.9 \%$ and $99.3 \%$ reductions in the growth of $A$. parasiticus and A. flavus, respectively, were determined when treated at $60 \mathrm{~W}$. Results showed complete disintegration of fungal spore membrane due to electroporation and etching caused by the reactive species of plasma. In $40 \mathrm{~W} 15 \mathrm{~min}$ and $60 \mathrm{~W} 12 \mathrm{~min}$ plasma treated samples more than $70 \%$ and $90 \%$ reduction in $\mathrm{AFB}_{1}$ content was observed as well. These results suggested that cold plasma may be considered as alternative methods for disinfestation of foods due to its strong potential for microbial inactivation. CAP can not only inactivate fungal growth but also degrade or remove mycotoxins such as $\mathrm{AFB}_{1}$, deoxynivalenol and nivalenol (Park et al., 2007) by microwave-induced argon plasma system at atmospheric pressure. Detoxication of $\mathrm{AFB}_{1}$ could be also achieved using nitrogen gas plasma treatment (Sakudo et al., 2017).

\section{Conclusion}

The biosynthesis of aflatoxins has been studied for more than 5 decades. Studies uncovered the functions of the enzymes involved in the aflatoxin biosynthesis, the genes encoding those enzymes, and the regulatory mechanisms of aflatoxin synthesis. Regulation of aflatoxin gene expression is carried out by multiple regulatory pathways. There are internal genetic factors, external biotic and abiotic factors that modulate aflatoxin formation. The genetic and genomic resources significantly enhanced our understanding of the mechanisms of aflatoxin biosynthesis and plant-fungus interactions. Further understanding of the gene regulation in aflatoxin biosynthesis will help with the identification of natural inhibitors of fungal growth and aflatoxin formation.

Several effective methods for prevention and control hazardous fungi and their dangerous products have been developed. The methods include biological control and physical and chemical treatments. Selection of fungal resistant cultivars has been recommended and used. Good agricultural practices have 
been essential in prevention of crop contamination by toxigenic fungal strains. Drying of commodities after harvest seems the most economical and effective means in agricultural industry. Chemical treatments such as alkalinization and ammoniation are well-recognized and industrially used. Novel non-chemical decontamination technologies have been developed such as microwave or low temperature plasma exposures. Eventually, more novel strategies to eliminate aflatoxin contamination for a safer, nutritious and sustainable food and feed supply will be introduced.

\section{Acknowledgments}

This work was supported by the Slovak Grant Agency VEGA No. 1/0904/14, the Slovak Research and Development Agency APVV-16-0216 and the Education Grant Agency KEGA 047STU-4/2016.

\section{References}

Al-Shahrani MH, Mahfoud M, Anvarbatcha R, Athar T, Asmari AA (2017) Pharmacognosy Communications 7: 34-40.

Amaike S, Keller NP (2011) Annual Review of Phytopathology 49: 107-133.

Arrus K, Blank G, Abramson D, Clear R, Holley RA (2005) Journal of Stored Products Research 41: 513-527.

Astani A, Reichling J, Schnitzler P (2010) Phytotherapy Research 24: 673-679.

Asters MC, Williams WP, Perkins AD, Mylroie JE, Windham GL, Shan X (2015) Scientific Reports 4: 4815 .

Astoreca A, Vaamonde G, Dalcero A, Marin S, Ramos A (2014) Food Microbiology 38: 276-283.

Atehnkeng J, Donner M, Ojiambo PS, Ikotun B, Augusto J, Cotty PJ, Bandyopadhyay R (2016) Microbial Biotechnology 9: 75-88.

Bayram Ö, Bayram ÖS, Ahmed YL, Maruyama J, Valerius O, Rizzoli SO, Ficner R, Irniger S, Braus GH (2012) PLoS Genetics 8: e1002816.

Bayram Ö, Braus GH (2012) FEMS Microbiology Reviews 36: 1-24.

Bayram O, Krappmann S, Ni M, Bok JW, Helmstaedt K, Valerius O, Braus-Stromeyer S, Kwon NJ, Keller NP, Yu JH, Braus GH (2008) Science 320: 1504-1506.

Bennett JW, Dunn JJ, Goldsman CL (1981) Applied and Environmental Microbiology 41: 488-491.

Bennett JW, Klich M (2003) Clinical Microbiology Reviews 16: 497-516.

Bhatnagar-Mathur P, Sunkara S, Bhatnagar-Panwar M, Waliyar F, Sharma KK (2015) Plant Science 234: 119-132.

Brown SH, Scott JB, Bhaheetharan J, Sharpee WC, Milde L, Wilson RA, Keller NP (2009) Molecular Plant-Microbe Interactons 22: 882-894.

Burow GB, Nesbitt TC (1997) Molecular Plant-Microbe Interactions 10: 380-387.

Caceres I, El Khoury R, Bailly S, Oswald IP, Puel O, Bailly JD (2017) Fungal Genetics and Biology 107: 77-85.
Calvo AM, Cary JW (2015) Frontiers in Microbiology 6: $1-16$.

Calvo AM, Wilson RA, Bok JW, Keller NP (2002) Microbiology and Molecular Biology 66: 447-459.

Cary JW, Han Z, Yin Y, Lohmar JM, Shantappa S, HarrisCoward PY, Mack B, Ehrlich KC, Wei Q, ArroyoManzanares N, Uka V, Vanhaecke L, Bhatnagar D, Yu J, Nierman WC, Johns MA, Sorensen D, Shen H, De Saeger S, Diana Di Mavungu J, Calvo AM (2015) Eukaryotic Cell 14: 983-997.

Cleveland TE, Yu J, Fedorova N, Bhatnagar D, Payne GA, Nierman WC, Bennett JW (2009) Trends in Biotechnology 27: 151-157.

Dasan BG, Mutlu M, Boyaci IH (2016) International Journal of Food Microbiology 216: 50-59.

Dehghanpour-Farashah S, Taheri P (2016) International Journal of New Technology and Research 2: 30-39.

Devi Y, Thirumdas R, Sarangapani C, Deshmukh RR, Annapure US (2017) Food Control 77: 187-191.

Dorner JW (2009) Peanut Science 36: 60-67.

Duran RM, Cary JW, Calvo AM (2009) The Open Mycology Journal 3: 27-36.

Fabbri AA, Fanelli C, Panfili G, Passi S, Fasella P (1983) Journal of General Microbiology 129: 3447-3452.

Fridman G, Friedman G, Gutsol A, Shekhter AB, Vasilets VN, Fridman A (2008) Plasma Processes and Polymers 5: 503-533.

Gallo A, Solfrizzo M, Epifani F, Panzarini G, Perrone G (2016) International Journal of Food Microbiology 217: 162-169.

Gao X, Kolomiets MV (2009) Toxin Reviews 28: 79-88.

Georgianna DR, Payne GA (2009) Fungal Genetics and Biology 46: 113-125.

Ghanghro AB, Channa MJ, Sheikh SA, Nizamani M, Ghanghro IH (2016) International Journal of Biosciences 8: 8-16.

Gilbert MK, Mack BM, Wei Q, Bland JM, Bhatnagar D, Cary JW (2016) Microbiological Research 182: $150-161$.

Giorni P, Battilani P, Pietri A, Magan N (2008) International Journal of Food Microbiology 122: 109-113.

Grintzalis K, Vernardis SI, Klapa MI, Georgiou CD (2014) Applied and Environmental Microbiology 80: 5561-5571.

Hicks JK, Yu JH, Keller NP, Adams TH (1997) EMBO Journal 16: 4916-4923.

Horn BW (2007) Food Additives and Contaminants 24: $1088-1101$.

Hruska Z, Rajasekaran K, Yao H, Kincaid R, Darlington D, Brown RL, Bhatnagar D, Cleveland TE (2014) Frontiers in Microbiology 5: 1-7.

Jayashree T, Subramanyam C (2000) Free Radical Biology and Medicine 29: 981-985.

Jiujiang Y, Chang P, Cary JW, Wright M, Bhatnagar D, Cleveland TE, Payne GA, Linz JE (1995) Applied and Environmental Microbiology 61: 2365-2371.

Kedia A, Dwivedy AK, Jha DK, Dubey NK (2016) Protoplasma 253: 647-653.

Kelley RY, Williams WP, Mylroie JE, Boykin DL, Harper JW, Windham GL, Ankala A, Shan X (2012) PLoS One. 7: e36892.

Khaledi N, Taheri P, Tarighi S (2015) Journal of Applied Microbiology 118: 704-717. 
Klich MA (2007) Molecular Plant Pathology 8: 713-722.

Kumar V, Basu MS, Rajendran TP (2008) Crop Protection 27: 891-905.

Kumeda Y, Asao T, Takahashi H, Ichinoe M (2003) FEMS Microbiology Ecology 45: 229-238.

Lanubile A, Maschietto V, Battilani P, Marocco A (2017) Journal of Plant Interactions 12: 21-30.

Lee SH, Park SY, Byun KH, Chun HS, Ha SD (2017) Food Additives \& Contaminants: Part A 34: 1193-1200.

Li Y, He Y, Li X, Fasoyin OE, Hu Y, Liu Y, Yuan J, Zhuang Z, Wang S (2017) Toxicon 127: 112-121.

Hong SY, Roze LV, Linz JE (2013) Toxins 5: 683-702.

Liu X, Guan X, Xing F, Lv C, Dai X, Liu Y (2017) Food Control 82: 325-332.

Lohmar JM, Harris-Coward PY, Cary JW, Dhingra S, Calvo AM (2016) Applied Microbiology and Biotechnology 100: 5029-5041.

Maplestone RA, Stone MJ, Williams DH (1992) Gene 115: 151-157.

Mehl HL, Cotty PJ (2011) Applied and Environmental Microbiology 77: 1691-1697.

Mehl HL, Cotty PJ (2010) Phytopathology 100: 150-159.

Meyers DM, Obrian G, Du WL, Bhatnagar D, Payne GA (1998) Applied and Environmental Microbiology 64: 3713-3717.

Molina M, Giannuzzi L (2002) Food Research International 35: 585-594.

Njobeh PB, Dutton MF, Koch SH, Chuturgoon A, Stoev S, Seifert K (2009) International Journal of Food Microbiology 135: 193-198.

Park BJ, Takatori K, Sugita-Konishi Y, Kim IH, Lee MH, Han DW, Chung KH, Hyun SO, Park JC (2007) Surface and Coatings Technology 201: 5733-5737.

Payne GA, Brown MP (1998) Annual Review of Phytopathology 36: 329-362.

Pekmezovic M, Rajkovic K, Barac A, Senerović L, Arsic Arsenijevic V (2015) Biochemical Engineering Journal 99: 131-137.

Reverberi M, Punelli M, Smith CA, Zjalic S, Scarpari M, Scala V, Cardinali G, Aspite N, Pinzari F, Payne GA, Fabbri AA, Fanelli C (2012) PLoS One 7: 1-15.

Reverberi M, Zjalic S, Ricelli A, Fabbri AA, Fanelli C (2006) Mycotoxin Research 22: 39-47.

Reverberi M, Zjalic S, Ricelli A, Punelli F, Camera E, Fabbri C, Picardo M, Fanelli C, Fabbri AA (2008) Eukaryotic Cell 7: 988-1000.

Ribeiro AB, Gonçalves A, Carrajola A (2006) Materials and Structures 39: 179-187.
Roze LV, Chanda A, Wee J, Awad D, Linz JE (2011) Journal of Biological Chemistry 286: 35137-35148.

Roze LV, Laivenieks M, Hong SY, Wee J, Wong SS, Vanos B, Awad D, Ehrlich KC, Linz JE (2015) Toxins 7: $1411-1430$

Sakudo A, Toyokawa Y, Misawa T, Imanishi Y (2017) Food Control 73: 619-626.

Samarajeewa U, Sen AC, Cohen MD, Wei CI (1990) Journal of Food Protection 53: 489-501.

Satterlee T, Cary JW, Calvo AM (2016) PLoS One 11: $1-18$.

Scarpari M, Punelli M, Scala V, Zaccaria M, Nobili C, Ludovici M, Camera E, Fabbri AA, Reverberi M, Fanelli C (2014) Frontiers in Microbiology 5: 1-9.

Shen Q, Zhou W, Li H, Hu L, Mo H (2016) PLoS One 11: $1-14$.

Temba BA, Fletcher MT, Fox GP, Harvey JJW, Sultanbawa Y (2016) Food Control 59: 708-713.

Torres AM, Barros GG, Palacios SA, Chulze SN, Battilani P (2014) Food Research International 62: 11-19.

Trail F, Mahanti N, Rarick M, Mehigh R, Liang SH, Zhou R, Linz JE (1995) Applied and Environmental Microbiology 61: 2665-2673.

Ueng YF, Shimada T, Yamazaki H, Guengerich FP (1995) Chemical Research in Toxicology 8: 218-25.

Varga J, Rigó K, Tóth B, Téren J, Kozakiewicz Z (2003) Food Technology and Biotechnology 41: 29-36.

Vicente J (2004) Revista de Economia e Sociologia Rural 42: 201-222.

Wang H, Lei Y, Yan L, Cheng K, Dai X, Wan L, Guo W, Cheng L, Liao B (2015) BMC Microbiology 15: 182.

Yang K, Liang L, Ran F, Liu Y, Li Z, Lan H, Gao P, Zhuang Z, Zhang F, Nie X, Kalayu Yirga S, Wang S (2016) Scientific Reports 6: 23259.

Yang K, Zhuang Z, Zhang F, Song F, Zhong H, Ran F, Yu S, Xu G, Lan F, Wang S (2015) Food Additives \& Contaminants: Part A 32: 554-563.

Yu J (2012) Toxins 11: 1024-1057.

Yu J, Chang P, Ehrlich KC, Cary JW, Bhatnagar D, Cleveland TE, Payne G, Linz JE, Woloshuk CP, Bennett W, Bennett JW (2004) Applied and Environmental Microbiology 70: 1253-1262.

Zaccaria M, Ludovici M, Sanzani SM, Ippolito A, Cigliano RA, Sanseverino W, Scarpari M, Scala V, Fanelli C, Reverberi M (2015) Toxins 7: 4315-4329.

Zahoranová A, Henselová M, Hudecová D, Kaliňáková B, Kováčik D, Medvecká V, Černák M (2016) Plasma Chemistry and Plasma Processing 36: 397-414. 